\title{
A Study on the Coordinated Development between New Urbanization and Service Industry in Hubei Province
}

\author{
Chun Liu ${ }^{1,2}$, Weizheng Jiang ${ }^{1}$ \\ ${ }^{1}$ Wuhan Technology and Business University, Department of Management, Wuhan 430065, China \\ ${ }^{2}$ Hubei Business Service Development Research Center, Wuhan 430065, China
}

\begin{abstract}
This paper selects two time series data on new urbanization and the contribution level of service industry to GDP in Hubei Province from 1998 to 2012. By unit root test, Johansen co-integration test and granger causality test analysis for the development of the urbanization and service industry time series, The test result shows that in the sample time interval, there is low negative correlation between urbanization level and the service industry in Hubei province, service industry to GDP in Hubei province is a one-way Granger cause of urbanization level, therefore, enhance the level of urbanization, at the same time, adhere to the development path of people-centered new urbanization, strengthen the service function of town in Hubei province.
\end{abstract}

Keywords: New urbanization; Service industry; Unit Root Test; Granger Causality Test; Hubei province.

\section{Introduction}

Urbanization is trend of civilization and symbol of modernization, which growth up with industrialization developing, settlement in non-agricultural and population concentration ${ }^{[1]}$. It is a great mission to adjust economy structure and optimize industrial structure by the means of developing service industry, which also fits the situation of opening policy and play an important role on comprehensive national strength promoting ${ }^{[2]}$. Focused on core cities especially megacities at modern service industry developing, strengthening core field of service industry of megacities, expanding center of regional service industry, rational distribution of commerce, trade and finances' functional area, forming industry structure by the leading of service industry as soon as possible ${ }^{[3]}$.

According to Unswervingly follow the path of socialism with Chinese characteristics and strive to build a well - off society in an all - round way in Nov. 2012, it reveals that stick to the way of new urbanization and agriculture modernization with Chinese characteristics. According to Some opinions of the State Council on accelerating the development of service industry in Mar. 2007, it reveals that service industry is an important part of national economy; service industry's developing is the significant of modernization. In the meeting of central urbanization in Dec. 2013, opinions like "urbanization is the necessity to modernization". Promoting urbanization is a powerful support to promote regional coordinated development, focusing on improving the proportion of service industry, enhancing urban innovation ability. In the National new urbanization plan (2014-2020) in Mar. 2014, it indicates that urbanization is closely related to service industry development, and service industry is the maximum capacity of employment. Population agglomeration in the process of Urbanization, the improvement of life style and the improvement of living standard, which will lead to expand the service needs of life.

This thesis is about the studying of coordinated development between urbanization and tourism in Hubei province by the means of Pertinence Analysis, Unit Root Test and Granger Causal Relation Test. providing the supporting and basis to Hubei government on development and implementation of the new urbanization and service industry development strategy in Hubei Province.

\section{Literature References}

"The spatial agglomeration of service industry and urban economic development is the mutual promotion relationship" was considered by Ma Peng (2010) ${ }^{[4]}$ and Qiu Ling (2012) ${ }^{[5]}$.Chu Mingqin (2013) ${ }^{[6]}$ had viewpoint of "The intensive utilization of urban land in our country by the 
agglomeration of productive service industry, and avoid the extensive use of urban land". Gu Yongfen (2013) ${ }^{[7]}$ pointed "The relationship between service industry agglomeration and economic growth in the Yangtze River delta urban agglomeration" by the means of Location Entropy; it reveals the government should pay attention to the transformation from "quantity" to "quality". Zhao Hongyun (2014) ${ }^{[8]}$ gave suggestion of boosting and coordinating between urbanization and service industry. It should promote the optimization and upgrading of the traditional service industry structure, at the same time; we should speed up the development of urban economy, and promote scientific and technological innovation.

According to Zheng qiongjie(2011) ${ }^{[9]}$, Li Chenhua(2012) ${ }^{[10]}$ and Li Fengchun(2013) $)^{[11]}$, they sorted out the interactive relationship between the development of modern service industry and urban transformation, discussing about how to accelerate the transformation and upgrading of the city with the development of modern service industry and Building service economy system. Zhang Zhibing (2012) ${ }^{[12]}$ put forward to develop the productive service industry to promote the sustainable development of urban economy through studying on the mechanism of the development of the urban productive service industry on the economic transformation.

Li jing (2011) ${ }^{[13]}$ reveals there is a single-track correlation between urbanization and employment in the service sector in Shandong province. However, the effect of urbanization on the employment level of the service sector has hysteresis. Cai Boliang (2012) ${ }^{[14]}$ studied on the path of the development of the city and the service industry. Zhang Zhibing (2013) ${ }^{[15]}$ stood on the point of division of labor theory, value chain theory and industrial agglomeration theory to analysis the influence mechanism of producer service industry and city coordinated development. Cui Hongqiao (2014) ${ }^{[16]}$ studied on the promotion of service industry to urbanization is much obvious, the service industry has a limited role in promoting urbanization, which two factors have not realized the positive interaction and coordinated development in Ji Lin province by the means of Gray correlation analysis.

Many literatures study mainly about the qualitative analysis of the relationship between the service industry and urbanization. At the same time, the quantitative research on the relationship between the development of service industry and the new urbanization in Hubei province is rare. In view of this, this thesis is based on the relevant data of urbanization level and service industry development in Hubei (1998-2012), and analyzes the relationship between the new urbanization level and service industry development by using the correlation analysis method, and analyzes the relationship between urbanization and tourism development in Hubei province by using the unit root test and Granger Causal Relation Test.

\section{Analysis Model}

\subsection{ADF Unit Root Test}

Unit root test and it always for $A D F$ unit root test use for testing a time series data is stable or not. $A D F$ unit root test as follow:

$$
\Delta y_{t}=\delta y_{t-1}+\sum_{i=1}^{m} \beta_{i} \Delta y_{t-1}+\varepsilon_{t}
$$

(1)In this model, $y$ represents for time series, $t$ represents for time variable, null hypothesis is $\delta=0$ and alternative hypothesis is $\delta<0$. If we accept the null hypothesis, we show that there is a unit root in $x$, which is a non stationary series, and the stationary sequence is stationary. For non-stationary sequences, if the order difference of $d$ is completed, the sequence is $d$ order or $I(d)$.

The test result of the null hypothesis of the model can be considered as a stationary sequence, and the model can be considered as a non stationary sequence.

\subsection{Co-integration Test of Johansen}

Co-integration means that a certain linear combination of multiple non-stationary economic variables is stationary, and if the number of non-stationary variables is in a co-integration, then these variables can be synthesized in a stationary sequence. The stationary sequence can be used to describe the equilibrium relationship among variables. The regression model established by these 
variables only has meaning, co-integration test of Johansen, and the test method is applied to the co-integration test. The test model is:

$$
y_{t}=\sum_{i=1}^{p} a_{i} y_{t-i}{ }^{+} \varepsilon_{t}
$$

(2)In this model, $y$ represents for endogenous variables vector of $\mathrm{T}$ dimension, a represents for matrix of coefficients, $P$ represents for the order number of the inner variable.

\subsection{Granger Causality Test}

Grainger causality test is some kind of method to investigate whether the time series $x$ is reason produced by time series $y$ : the current $y$ value is estimated to be the extent of its own lag can be explained by the introduction of the lag value of $x$ sequence, it is verified by the introduction of the delay value of the $x$ sequence to improve the degree of the $y$. If it is, Sequence $x$ is the (Cause Granger) of $y$ and the lag coefficient of $x$ is statistically significant at this time. In general, it should also consider the other side of the problem: the sequence of $y$ is the cause of the Grainger $x$. The following two regression models are estimated:

The Model of Unrestricted Conditional Regression:

$$
y_{t}=\sum_{t=1}^{m} a_{t} y_{t-1}+\sum_{t=1}^{m} b_{t} x_{t-1}+\varepsilon_{t}
$$

The Model of Restricted Conditional Regression:

$$
y_{t}=\sum_{t=1}^{m} a_{t} y_{t-1}+\varepsilon_{t}
$$

The model of (3) and (4), if the test coefficient ${ }_{b_{1} \ldots b_{m}}$ is significantly less than 0 , the null hypothesis is rejected, which indicates that $y^{\prime}$ s change of Granger is caused by $x$; when the null hypothesis is " $y$ is not the Granger cause of $x^{\prime}$ s change", $y$ and $x$ in the two regression models are interchangeable.

Tab.1 the Date of Urbanization Development Level in Hubei from 1998 to 2012

\begin{tabular}{ccccccc}
\hline Year & $\begin{array}{c}\text { Total population } \\
\text { (million) }\end{array}$ & $\begin{array}{c}\text { Urban population } \\
\text { (million) }\end{array}$ & $\begin{array}{c}\text { Gross Regional } \\
\text { Product(hundred } \\
\text { millinnman }\end{array}$ & $\begin{array}{c}\text { Service industry added } \\
\text { value (hundred million }\end{array}$ & UR(\%) & SCR(\%) \\
\hline 1998 & 5907.23 & 1884.41 & 3114.02 & 1136.71 & 31.90 & 36.50 \\
1999 & 5938.03 & 1990.17 & 3229.29 & 1260.86 & 33.52 & 39.00 \\
2000 & 5646.00 & 2285.11 & 3545.39 & 1445.71 & 40.47 & 40.80 \\
2001 & 5658.00 & 2308.50 & 3880.53 & 1613.97 & 40.80 & 41.60 \\
2002 & 5672.00 & 2348.20 & 4212.82 & 1795.93 & 41.40 & 42.60 \\
2003 & 5685.00 & 2387.70 & 4757.45 & 2003.08 & 42.00 & 42.10 \\
2004 & 5698.00 & 2427.30 & 5633.24 & 2292.55 & 42.60 & 40.70 \\
2005 & 5710.00 & 2466.70 & 6590.19 & 2655.94 & 43.20 & 40.30 \\
2006 & 5693.00 & 2493.50 & 7617.47 & 3111.98 & 43.80 & 40.90 \\
2007 & 5699.00 & 2524.70 & 9333.40 & 3812.34 & 44.30 & 40.80 \\
2008 & 5711.00 & 2581.40 & 11328.92 & 4466.85 & 45.20 & 39.40 \\
2009 & 5720.00 & 2631.20 & 12961.10 & 5127.12 & 46.00 & 39.60 \\
2010 & 5723.77 & 2846.13 & 15967.61 & 6053.37 & 49.72 & 37.90 \\
2011 & 5758.00 & 2984.32 & 19594.19 & 7206.13 & 51.83 & 36.80 \\
2012 & 5779.00 & 3091.77 & 22250.16 & 8210.94 & 53.50 & 36.90 \\
\hline
\end{tabular}

\section{Empirical Analyses}

\subsection{Data Sources and Processing}

This paper relates to the new urbanization and service industry data of Hubei province from 1998 to 2012. In this paper, the proportion of urban population to the total population as a new type of urbanization level indicators with $U R$ representatives; the proportion of service industry added value to GDP as the development of the service sector with SCR representatives. Raw data from The Hubei Province Statistical Yearbook in 2013 and The Report for The Service Industry Development of Hubei Province in 2013. 
In this paper, the date of the total population, urban population, GDP and service industry added value in Hubei province from 1998 to 2012 were used, the SCR and UR data are shown in Table 1.

From Figure 1 it can be seen that $U R$ has a trend of increasing, and SCR has a trend of fluctuation.

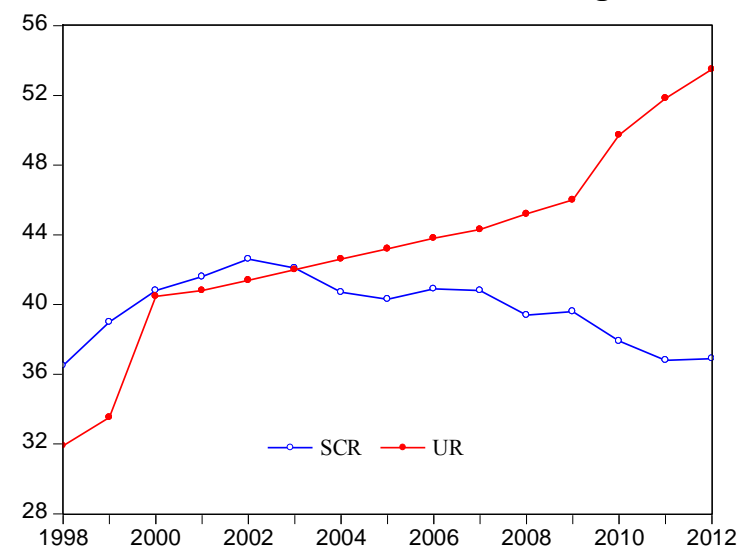

Fig. 1 the Trend Change between UR and SCR

\subsection{ADF Unit Root Test}

In this paper, the $A D F$ test method is used to test the unit root of $U R$ variable and SCR variable, and taking the logarithm from UR and SCR are expressed by LnSCR and LnUR. The results of test are shown in Table 2.

Table 1 the Results of ADF Unit Root Test

\begin{tabular}{ccccc}
\hline Variables & ADF Test value & Critical Value of 5\% & DW & Results \\
\hline LnUR & 2.804112 & -1.96843 & 1.902211 & Unstable \\
LnUR-1 & -2.348003 & -1.970978 & 1.840075 & Stable \\
LnSCR & 0.075076 & -1.96843 & 0.818264 & Unstable \\
LnSCR-1 & -2.873532 & -1.970978 & 2.169361 & Stable \\
\hline
\end{tabular}

Note: the subscript "-1" said one order difference.

The ADF test is carried out by the time series of $L n S C R$ and $L n U R$, the time series of the variables LnSCR and LnUR are more than 5\% critical values. However, after the difference, the difference between LnSCR and LnUR is less than $5 \%$ significance, So it can be seen that the first order difference of the logarithm of $U R$ and SCR is stable, that is, I (1).

\subsection{Co-integration Test of Johansen}

Table 3 shows that the rate of urbanization and service industry's contribution rate of Johansen test, the table is the test results of trace statistics.

Table 3 Co-integration Test of Johansen

\begin{tabular}{ccccc}
\hline Hypothesis & Characteristic & Trace Statistics & Critical Value of 5\% & Probability $(P)$ \\
\hline None $*$ & 0.978214 & 50.41238 & 15.49471 & 0.0000 \\
At most 1 & 0.050104 & 0.66824 & 3.84147 & 0.4137 \\
\hline
\end{tabular}

Note: None: no co-integration relationship; At most 1: a co-integration relationship.

The contribution rate of urbanization and service industry in Hubei province show no co-integration relationship, the test results of trace statistics is 50.41238 , critical value of more than $5 \%$ is 15.49471 , probability is 0 , which show the result reject the original hypothesis, that at least there is a co-integration relationship; The next original hypothesis is At most 1 there is a co-integration relationship at most, critical value of more than $5 \%$ is 3.84147 , the result accept the original hypothesis; So there is a co-integration relationship between the rate of urbanization and service industry in Hubei province.

\subsection{Granger Causality Test}

LnUR and LnSCR are I (1) by the results of the unit root test, which show that the two variables is stationary sequence. Johansen co-integration test shows that there is a long-term co integration relationship between the rate of urbanization and service industry in Hubei province. But cannot 
explain the causal relationship between the two variables. In this paper, the logical relationship between the two is explained by the Grainger causality test. Shown in Table 4.

Table 4 Granger Causality Test

\begin{tabular}{cccc}
\hline Causality Hypothesis & $F$ & $P$ & result \\
\hline LnUR is not the reason of $\operatorname{LnSCR}$ & 1.29876 & 0.3247 & accept \\
LnSCR is not the reason of $\operatorname{LnUR}$ & 15.5626 & 0.0017 & reject \\
\hline
\end{tabular}

Note: lag period 2

The results of Granger causality test show that, at the condition of significance is less than 5\% and lag period for 2 years, $L n U R$ is not the reason of $L n S C R, L n S C R$ is the reason of $L n U R$, there is a one-way causal relationship between $L n S C R$ and $L n U R$. It reveals that the development of service industry has a negative effect on the level of urbanization, but the development of the service industry is not directly caused by the development of urbanization. It indicates that the development of urban service functions of urban development has not played a role in the development of urbanization in Hubei Province, which restricts health and stable development of urbanization.

\section{Conclusions}

The results of this paper show that the development of urbanization has a strong negative correlation with service industry, and stationary time series for a first order differential variable. The development level of service industry is the Granger reason of urbanization development, and the development of urbanization is not the Granger cause of the development of urban service industry. Hubei province improves the level of urbanization simultaneously meanwhile need to adhere to the new path of people-oriented urbanization development, strengthen the service function of the city, and improve the quality of life of residents.

\section{Acknowledgment}

The authors acknowledge the research grants from the Special Research Program launched by Wuhan Technology and Business University (S2013001).

Corresponding author: LIU Chun, Wuhan Technology and Business University, Department of Management, Wuhan 430065, CHINA

\section{References}

[1] CPC Central Committee, the State Council. National new urbanization plan (2014-2020) [EB/OL]. http://www.gov.cn/gongbao/content/2014/content_2644805.htm (2014-03-16)

[2] The State Council. Development of service industry"Twelfth Five Year Plan"[EB/OL]. $\mathrm{http}: / / \mathrm{www} . g o v . c n /$ zwgk/2012-12/12/content_2288778.htm(2012-12-1)

[3]Zhou Feng. Accelerate the innovation and development of modern service industry [J]. Macroeconomic Management, 2013(1):46-47.

[4] MA Peng LI Wen-xiu. Services Spatial Agglomeration and Urban Economy Development [J]. Journal of Zhongnan University of Economics and Law, 2010(3):87-93.

[5] QIU Ling, FANG Chuang-lin. Study on the Spatial Agglomeration of Producer Services and Urban Development [J]. Economic Geography, 2012, 32(11):76-80.

[6] Chu Ming-qin. Cluster of Producer Services and Land Intensive Use of Cities [J]. Taxation and Economy, 2013(4):13-16.

[7] GU Yong-fen, Hong Juan. Agglomeration and economic growth of urban agglomeration service industry -- Taking the Yangtze River Delta as an example [J]. Jiangxi Social Sciences, 2013(4):43-47.

[8] ZHAO Hong-yun. Study on the relationship between the development of Chinese urbanization and service industry agglomeration [J]. Business Economy, 2014(2):6-7. 
[9] ZHENG Qiong-jie, LI Cheng-hua. Examining and thinking of relationship between modern service industry and city transformation [J].Urban Problems, 2011(12):9-15.

[10] LI Cheng-hua. Modern Service Industry Promotes Urban Transformation: Strategic Lead and Path Breakthrough [J]. Jianghai Academic Journal, 2012(2):87-92.

[11] LI Feng-chun, LI Chen-hua. The mechanism and Path of modern service industry promoting urban transformation in the perspective of "Four modernizations integration" [J]. Shanghai Journal of Economics, 2013(12):22-30.

[12] ZHANG Zhi-bin, ZHANG Si-mei. Research on the development of productive service industry and the transformation of urban economic structure [J].Search, 2012(4):32-34.

[13] LI Jing, LIU Ying-ji. An empirical analysis on the employment of the service industry in the process of Urbanization_- Taking Shandong Province as an example[J]. Hubei Social Sciences, 2011(10):85-88.

[14] CAI Bo-liang. Interactive Development of the Central Cities in Jiangsu Coastal Regions and the Service Industry: Problems and Countermeasures [J].Urban Studies, 2012, 19(4):24-26.

[15] ZHANG Zhi-bin. Review and Prospect of research on the coordinated development of producer services and urban [J].Economic Review, 2013(2):121-124.

[16] CUI Hong-qiao, SHEN Song-dong. Grey correlation analysis of urbanization and service industry in Jilin Province [J].Contemporary Economic Research, 2014(2):28-32. 